\title{
Digitally Modulated Higher Cervical Tetraplegic by facial Signaling Project
}

\author{
Abbas Alnaji* \\ Consultant neurosurgeon, Iraq \\ *Corresponding author: Abbas Alnaji, Consultant neurosurgeon, Iraq \\ Submission: 觜 August 21, 2017; Published: 㘹 September 25, 2017
}

\begin{abstract}
Complete tetraplegia means shoulder is involved due to cervical spinal cord segment four is damaged. We have to bypass this gap. One method is by picking up the signals of facial muscles where volitionally controlled, propagate them (afferent similarity) to a digital processor to generate a package of orders (efferents) transmitted to the effecter organs (muscles) to achieve preprogrammed task. The whole story is implanted sub-cutanously.
\end{abstract}

Keywords: Tetraplegia; Quadriplegia; Digital; Facial; Muscles; Afferent; ; microanatomist

\section{Introduction and Method}

In 1994 I were a second year resident in neurosurgery, A bout of young males with cervical fractures ( about 6 in number in twenties of age) admitted to our center in Baghdad in interval of 3 months, all due to jumping to swim in different situations and places [1-10]. Three of them were with C3 fracture and immediate quadriplegia, developed RDS and couldn't adapt for this in spite of non-surgical supportive measures, so died. The other 3 patients came with C4 fractures; they overcome the RDS with the same supportive measures to end with complete quadriplegia they stay alive for long in a tragic situation. It was very sad for a joiner resident like me. This triggered all my mental powers to help them. At that time there were no implantable chips to be put in or on brain motor cortex to pick up a signals to a limb sleeve through computer aid* [10-20]. So my plan was to pick up a patient's will signal from what has been left for him as a motor function, here it is available in numerous facial muscles. He still can control them. So in a manner similar to electromyography EMG studies we can record a signal or a group of signals in one activity like blinking or any other simple facial task through implanted non metallic electrodes to a implanted microcomputer to generate from this single impulse a package of patterned impulses conveyed also by non metallic (electro-conductive polymers) ${ }^{* *}$ electrodes to a related group of muscles everywhere in the body by subcutaneous tunnels like that done by neurosurgeons when passing the ventricloperitoneal shunt catheter from the burr hole done in the skull of the hydrocephalus patient down to the abdomen where the peritoneal cavity lies. This group of muscles receive the synchronized electric pulses to perform some task or function like lifting a glass of water and approximate it to the mouth for drinking, or to make lower limb auto- physiotherapy (active movements) and so on [21-25].

This project was written in 1996 and sent to Canada for evaluation or to be applied by some research center, a friend who is a medical doctor and he runs a medical trading company came to Iraq to work with the Iraq-UN memorandum of understanding of oil VS food, he was live and work in Canada, Iraq was under UN blockade so we cannot perform such project, unfortunately to date we cannot apply our thoughts!!! [25-31].

Six months later I heard part of this project is worked on by 5 teams from all over the world cooperate to perform it, when I called this friend by land phone who took it to Canada he informed me that when he disclosed it to a neurosurgeon, the later informed my friend that this project is being worked on before 2 months from this date, so it is not a new. I stopped thinking in this project. But as time passes I did not hear any hint about such project which was termed "FREE LIMBS" or "FREE HANDS" [32-40]. However several years I found some informations about it in the net but now I wonder no notice in many search engines to make it as a reference. I cannot say it is not exist because I heard about it by chance from Iraqi doctor who migrated to UK and became the head of spinal cord injured patients there in 1996, he came to Iraq in an attempt to brief us about their work in UK and the recent advances in the world which it was my project!!!

\section{Discussion}

This project combines many arts in surgery and basic sciences like electrophysiology, computer programming science and engineering, microelectronics with nanopolymers***. Neurosurgeon, plastic surgeon, faciomaxilary and orthopedic surgeon. This team of surgeons work together with the electro physiologist to make the beginning of the pathway in quadriplegic facial muscles where electrodes should be put to pick up a signal from certain muscles not usually the patient use them in a daily expressive facial movements, like the signature at the end of a written text, where signature is done when and where it is needed 
and of course it is a personal will [41-46]. We need to design a microchip to be embedded into the selected trigger muscle (facial) this chip have to be capable of send its (dendrites) to as much as muscle fibers. This chip act as synaptic system. By this we may be in need of anatomist and let us say a new brand a "microanatomist". By coming to the conveying wires, which are usually metal, it is used to use gold or silver. A relative new science, electro conductive polymers**, brought to us polymers which are organic non metallic with very good flexibility and biologically friendly can transmit electricity near that of metals. Another option we can use fiber optics to transmit laser signals these fibers are inert, flexible and not need isolation, so we need laser technology sciences. These conveyers (efferents) are passing under skin by tunneling to reach a digital processor also imbedded under skin this processor when receive this signal/s generates a preprogrammed cascade of pulses transmitted to effecter organs which are the muscles in limbs by efferent conveyers. Here also, we need some array of signals distributed to more muscle fibers for suitable powerful contraction.

This is an old technique by getting the signal from facial muscles rather than directly from brain motor cortex*. But it has advantages like less damage in less vital structures like brain cortex, less chance of intracranial infection and hemorrhage. Cortical implants will stay as a spare choice. The whole system here is subcutaneous so no matter of infections in exit-inlet sites and no sleeves covering the wanted limb, if we want moving the whole body we need to cover the body with what is similar to war shields.

\section{Recommendation}

We need to give life to this project by overcoming the difficulties had lead to its discontinuation. For that I ask the interested communities who are interested in lessen the sufferings of such tragic conditions of Tetraplegics to make some real and practical communication with me to put the plans for the details of each step in order to bring it to light. Due to chronic problems in Iraq, my country, where I reside, unfortunately these events does not allow us performing such giant steps.

\section{References}

1. https://wexnermedical.osu.edu/blog/neuroprosthetics-allow-ian-tomove-paralyzed-limb-with-power-of-thought

2. http://www.nature.com/nature/journal/v533/n7602/full/ nature17435.html

3. Inzelt, György (2008) Chapter 1: Introduction. In: Scholz F (Ed.), Conducting Polymers: A New Era in Electrochemistry. Monographs in Electrochemistry. Springer, pp. 1-6.

4. Naarmann, Herbert (2000) Ullmann's Encyclopedia of Industrial Chemistry. p. 3.

5. Nalwa HS (2000) Handbook of Nanostructured Materials and Nanotechnology. In: Nalwa HS (Ed.), Academic Press, New York, USA, 5: 501-575.

6. Inzelt, György (2008) Chapter 8: Historical Background (Or: There Is Nothing New Under the Sun). In: Scholz F (Ed.), Conducting Polymers: A New Era in Electrochemistry. Monographs in Electrochemistry, Springer, pp. 265-267.

7. Hush NS (2003) An Overview of the First Half-Century of Molecular Electronics. Ann N Y Acad Sci 1006: 1-20.
8. Okamoto Y, Brenner W (1964) Organic Semiconductors, Rheinhold, Germany.

9. Hideo A, Hiroo I, Yoshio M (1954) Electrical Conductivity of the PeryleneBromine Complex. Nature 173(4395): 168-169.

10.John SF, Cowan DO, Walatka V, Perlstein JH (1973) Electron transfer in a new highly conducting donor-acceptor complex. Journal of the American Chemical Society 95(3): 948-949.

11.Little WA (1964) Possibility of Synthesizing an Organic Superconductor Physical Review 134(6A): A1416.

12. Bolto BA, McNeill R, Weiss DE (1963) Electronic Conduction in Polymers. III. Electronic Properties of Polypyrrole. Aust J Chem 16(6): 1090.

13. Okamoto Y, Brenner W (1964) Organic Semiconductor. Chapter 7: Polymers, Reinhold, pp. 125-158.

14. Surville DR, Jozefowicz M, Yu LT, Pepichon J, Buvet R, et al. (1968) Electrochemical chains using protolytic organic semiconductors. Electrochimica Acta 13(6): 1451-1458.

15.Diaz A, Logan J (1980) Electroactive polyaniline films. Journal of Electroanalytical Chemistry 111(1): 111-114.

16. Hideki S, Edwin JL, Alan GM, Chwan KC, Alan JH, et al. (1977) Synthesis of electrically conducting organic polymers: Halogen derivatives of polyacetylene, $(\mathrm{CH}) \mathrm{x}$. Journal of the Chemical Society, Chemical Communications (16): 578.

17.(2000) The Nobel Prize in Chemistry.

18. Burroughes JH, Bradley DDC, Brown AR, Marks RN, MacKay K, et al. (1990) Light-emitting diodes based on conjugated polymers. Nature 347(6293): 539-541.

19. Friend RH, Gymer RW, Holmes AB, Burroughes JH, Marks RN, et al. (1999) Electroluminescence in conjugated polymers. Nature 397(6715): 121-128.

20.Heeger AJ, Schrieffer JR, Su WP, Su W (1988) Solitons in conducting polymers. Reviews of Modern Physics 60(3): 781-850.

21. Heeger AJ (1997) Nature of the primary photo-excitations in poly (arylene-vinylenes): Bound neutral excitons or charged polaron pairs, in Primary photo excitations in conjugated polymers: Molecular excitons versus semiconductor band model. In: Sarıçiftçi NS (Ed.), World Scientific, Singapore.

22. Nalwa HS (1997) Handbook of Organic Conductive Molecules and Polymers. In: Nalwa HS (Ed.), Handbook of Organic Conductive Molecules and Polymers, John Wiley \& Sons Ltd, Chichester, England, Vol 1-4.

23. Skotheim TA, Elsenbaumer RL, Reynolds JR (1998) Handbook of Conducting Polymers. Marcel Dekker Inc., New York, USA, Vol 1-2.

24. Hadziioannou G, Hutten PFV (2007) Semiconducting Polymers. WileyVCH, Weinheim, Germany.

25.Sariciftci NS, Smilowitz L, Heeger AJ, Wudl F (1992) Photoinduced Electron Transfer from a Conducting Polymer to Buck minster fullerene. Science 258(5087): 1474-1476.

26.Sirringhaus H (2005) Device Physics of Solution-Processed Organic Field-Effect Transistors. Advanced Materials 17(20): 2411-2425.

27. Yannoni CS, Clarke TC (1983) Molecular Geometry of cis- and transPolyacetylene by Nutation NMR Spectroscopy. Physical Review Letters 51(13): 1191-1193.

28. Skotheim T, Elsenbaumer R, Reynolds J (1998) Handbook of Conducting Polymers ( $2^{\text {nd }}$ edn), In: Skotheim T, Elsenbaumer R, Reynolds J (Eds.), Marcel Dekker Inc., New York, USA.

29. VenugopalanV ADR, Narayan KS (2011) In situ studies of strain dependent transport properties of conducting polymers on elastomeric substrates. J Appl Phys 109(8): 084525. 
30. Michael DV, Tee CK, Bolander JA, Zhenan B (2012) Electronic Properties of Transparent Conductive Films of PEDOT: PSS on Stretchable Substrates. Chem Mater 24(2): 373-382.

31.Ulrich L, Nataliya VR, Mirsky VM (2008) Conducting polymers in chemical sensors and arrays. Analytica Chimica Acta 614(1): 1-26.

32. Nalwa HS (2000) Handbook of Nano structured Materials and Nanotechnology. In: Nalwa HS (Ed.), Academic Press, New York, NY, USA, 5: 501.

33. Overview on Organic Electronics.

34. Organic Electronics Association.

35.(2011) Conjugated Polymers: Electronic Conductors.

36.Cassoux P (2001) Molecular Metals: Staying Neutral for a Change. Science 291(5502): 263-264.

37. Hush NS (2003) An Overview of the First Half-Century of Molecular Electronics. Annals of the New York Academy of Sciences 1006: 1-20.

38.Bendikov M, Wudl F, Perepichka DF (2004) Tetrathiafulvalenes, oligoacenenes, and their buckminsterfullerene derivatives: the brick and mortar of organic electronics (PDF). Chem Rev 104(11): 4891-4946.

39. Hyungsub Ch, Mody CM (2009) The Long History of Molecular Electronics Social Studies of Science, 39(1).
40. Oberlin A, Endo M, Koyama T (1976) Filamentous growth of carbon through benzene decomposition. Journal of Crystal Growth 32(3): 335349.

41. Carter FL, Siatkowski RE, Wohltjen H (1988) Molecular Electronic Devices. In: Carter FL, Siatkowski RE, Wohltjen H (Eds.), North Holland, Amsterdam, Netherlands, pp. 229-244.

42. Greiner A, Wendorff JH, Yarin AL, Zussman E (2006) Bio hybrid nanosystems with polymer nanofibers and nanotubes. Applied Microbiology and Biotechnology 71(4): 387-393.

43. Lalwani G, Henslee AM, Farshid B, Lin L, Kasper FK, et al. (2013) Twodimensional nanostructure-reinforced biodegradable polymeric nanocomposites for bone tissue engineering. Biomacromolecules 14(3): 900-909.

44. Lalwani G, Henslee AM, Farshid B, Parmar P, Lin L, et al. (2013) Tungsten disulfide nanotubes reinforced biodegradable polymers for bone tissue engineering. Acta Biomater 9(9): 8365-8373.

45. Godovsky DY (2000) Device Applications of Polymer-Nanocomposites. In: Chang, JY (Ed.), Biopolymers PVA Hydrogels, Anionic Polymerisation Nanocomposites. Advances in Polymer Science, pp. 163-205.

46. Lang, XY, Zhang GH, Lian JS, Jiang Q (2006) Size and pressure effects on glass transition temperature of poly (methyl methacrylate) thin films. Thin Solid Films 497(1-2): 333-337. 